Research Article

\title{
Research on In Situ Stress Measurements in Reinforced Concrete Beams Based on the Core-Drilling Method
}

\author{
Nian-Chun Deng ${ }^{1,2}$ and Peng-Fei Tang $\mathbb{1 D}^{1}$ \\ ${ }^{1}$ College of Civil and Architectural Engineering, Guangxi University, Nanning 530004, China \\ ${ }^{2}$ Guangxi Key Laboratory of Disaster Risk Reduction and Engineering Safety, Nanning 530004, China
}

Correspondence should be addressed to Peng-Fei Tang; tpf@st.gxu.edu.cn

Received 20 March 2020; Revised 11 July 2020; Accepted 17 July 2020; Published 6 August 2020

Academic Editor: Pier Paolo Rossi

Copyright (c) 2020 Nian-Chun Deng and Peng-Fei Tang. This is an open access article distributed under the Creative Commons Attribution License, which permits unrestricted use, distribution, and reproduction in any medium, provided the original work is properly cited.

\begin{abstract}
To increase the accuracy of the core-drilling method in measuring the in situ stresses within concrete beams, this paper developed a special core-drilling machine system, studied the surface stress release rule of concrete beams through finite element simulations, and then carried out verification tests. The effects of the borehole diameter, drilling depth, strain sensor size, and borehole position on the measurement accuracy were studied. The results showed that borehole diameters of $100 \mathrm{~mm}, 75 \mathrm{~mm}$, and $50 \mathrm{~mm}$ can achieve stress release and that the smaller the borehole diameter was, the easier it was to release the stress. When using the smallest borehole, the stress concentration range around the borehole was narrow, and there was little damage to the original structure. The strain gauge size influenced the actual measurement results. An excessively large strain gauge will be disturbed by drilling because of the limited size of the borehole. An excessively small strain gauge will be easily influenced by the inhomogeneity and randomness of the concrete materials, resulting in large measurement error. The difference between the measured concrete stress and the theoretical value was less than $10 \%$, and the average error was only $6.03 \%$, indicating the feasibility of the proposed method.
\end{abstract}

\section{Introduction}

Many buildings in the world have reached their intended lifespan. For example, China has built approximately 805,300 highway bridges [1], for which the number of repairs required is increasing daily. More than 100,000 highway bridges are considered at risk [2]. Accurate assessment of the in situ stress within concrete structures is very important for ensuring their safety and reliability [3-6]. In the lifespan of concrete structures, stress attenuation, concrete creep, construction deviation, and uneven support settlement create transient stress variations [4]; hence, the theoretical calculation of the stress within a structure is always much different from the actual stress. The evaluation of actual stress is tedious and difficult $[3,5,7]$. Many scholars have conducted a substantial number of studies in this field. The authors of $[3,8]$ summarize the existing various stress detection methods, and according to experimental analysis, some of these methods are not suitable for existing structures in service. Hence, considerable work is required before these techniques can be applied in actual engineering applications [9].

The stress relief method is an effective method for measuring structural stress [1] and has been a popular research topic in recent years [3]. The stress relief method includes the slicing method, the drilling method, and through-hole drilling method $[3,10]$. The drilling method was originally proposed by Mathar [11] in 1934 and is widely used to measure the residual stress in metal material components [12-14]. Typically, the drilled hole is small (approximately $1.5 \mathrm{~mm}$ in diameter), so the method does not work well for concrete because the use of small strain gauges is complicated by the heterogeneity of the material [15]. Later, Mehrkar-Asl [16] proposed a borehole stress release technique for determining the in situ stress within concrete structures. Pesski [17] and Turker [18] attempted to apply 
the core-drilling method (CDM) to concrete by using large through holes (the diameter is approximately $100 \mathrm{~mm}$ ). However, experiments have shown that this method is subjected to many interference factors when applied to concrete $[1,19]$, resulting in an unsatisfactory accuracy (error greater than 10\%) [9].

McGinnis $[15,20]$ combined the CDM with digital image correlation (DIC) [7], and considering the effects of water, concrete shrinkage, and steel reinforcement, the average error in the experiments dropped from $28.4 \%$ to 9.5\%. Trautner [6] applied the influence function (IF) $[21,22]$ to the CDM, verified the accuracy of the technique through finite element simulations, and obtained the stress field distribution along the thickness direction. In 2011, they combined the IF, the CDM, and DIC, and their results showed that this method can accurately determine the in situ stress distribution within simple concrete structures. In addition, Trautner also tested three simple posttensioned beams. Their results showed that the accuracy of the measurement of the top fiber stress was within approximately $10 \%$, whereas that of the measurement of the variation in stress with respect to depth was within approximately $22 \%$; however, further work was needed to determine the implications of these observations [23]. Ruan and Zhang [4, 24] adopted a combination of CDM and IFs to provide a nondestructive method of using strain gauges to determine the uniaxial in situ stress within existing concrete components of bridges. Their results showed that the stress identification accuracy was within $10 \%$ and that the accuracy of the proposed method may vary with respect to the size of the core and the size of the sensitive grid of the strain gauge; moreover, further optimization is possible. At present, most studies performed under ideal conditions, such as theoretical calculations $[8,25]$ and simulations $[9,26-28]$, have led to relevant theories, such as stress release rules; however, these theories are not yet mature in engineering applications [29].

Yong [10] conducted an in situ stress assessment of the Wuhe-Huaihe Bridge, and Santiago [30] conducted a similar assessment at the Berlin Atles Museum. Their results showed that the stress relief method can be applied to in-service projects. Kesavan [31] and Parivallal [32] proposed the borehole testing technique of applying strain gauges to the center of the concrete borehole and around the borehole wall, which was suitable for unidirectional prestressed concrete beams but did not solve the problems of the wiring and vulnerability of the strain gauges located in the borehole. At present, the strain gauges are pasted outside of the borehole $[33,34]$ because the strain information in the borehole cannot be continuously output.

This article proposes a new system that combines strain gauges with a core-drilling machine to measure the released strain. This system can solve the problem of borehole strain gauge wiring and can achieve continuous measurement of the strain released by the CDM. In addition, various factors affecting the measurement accuracy are considered in the study, wherein the primary focus is on the effects of the borehole size, strain gauge sensitive grid size, and initial stress value on stress evaluation to improve measurement accuracy and engineering practicability. Through three- dimensional finite element analysis (FEA) software, the process of releasing the surface stress from a uniaxially stressed concrete beam by the CDM was simulated and experimentally verified. The results showed that the error between the estimated stress and the theoretical stress can be within $10 \%$ and that the average error was only $6.03 \%$, which can achieve engineering stability and reliable operation. Hence, the proposed method can be used to measure the in situ stress within uniaxially stressed reinforced concrete beams, thereby providing a basis for structural evaluation and reinforcement maintenance.

\section{Materials and Methods}

2.1. Basic Theory. The CDM is a type of local damage method that can be used to evaluate the in situ surface stress within a concrete structure. During the drilling process, the stress in and around the borehole wall is gradually released, and the concrete around the measuring point is subjected to elastic deformation. The electronic strain sensor is fastened to the measuring point according to the in situ stress direction. As the depth of the borehole increases, the strain sensor measures the elastic strain released by the concrete. The in situ stress is completely released once the borehole reaches a certain depth. According to the strain change measured at a certain time, the in situ stress within the structural member can be calculated through the elastic modulus of the concrete.

For a structural member in the direction of the uniaxial stress field, only the adhesive direction of the strain sensor needs to be parallel to the direction of the internal force. The strain change measured at the measurement point can be used to calculate the magnitude of the in situ stress at that point, as shown in Figure 1. Therefore, the unidirectional stress can be calculated by

$$
\sigma=E \varepsilon
$$

where $E$ denotes the elastic modulus and $\varepsilon$ denotes the strain.

The uniaxial strain is measured with a resistance strain gauge, for which the rate of change in the relative resistance is directly proportional to the strain. The standard resistance of $120 \Omega$ is most commonly used, including temperature compensation using specific sample material compensation methods and resistance strain gauges that measure multiple specifications.

2.2. Special Core-Drilling Measurement System. To solve some of the problems in determining the in situ stress within concrete, we developed a special core-drilling measurement system that consists of a core drill and a measurement system. The core-drilling machine is fixed to the structural member being tested through the base, which is connected with a stable bolt and a vertical column; the core-drilling machine and the structural member are balanced by the bolt. The machine body is connected to a vertical column and an elevating rack, and the motor, drill barrel, and protective housing are all arranged on the machine body. The engine is connected to the driving wheel, which drives the rotation of 


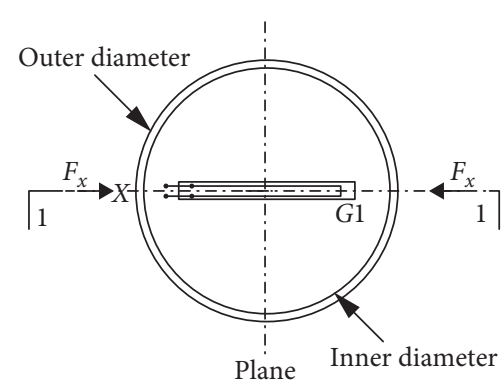

(a)

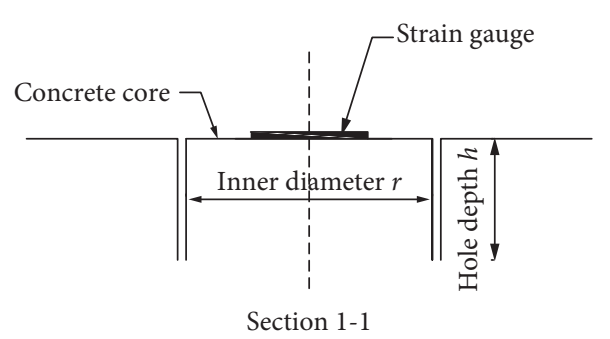

(b)

FIGURE 1: Strain gauge arrangement for uniaxial stress conditions.

the slave wheel through the belt, which subsequently drives the rotation of the drill barrel. The machine body has a handle that can lift or lower the body, which can be used to adjust the depth of the drill hole. The strain sensor is fastened to the surface of the measuring point at the front of the drill barrel, and the signal line can be connected to the sensor and the strain measuring system through the machine body and drill barrel. The strain measurement system consists of a signal demodulator, a computer readout, and a temperature compensation block. The strain sensor can measure the released strain in real time through the measuring system. After the strain measurement is completed, the core sample can also be removed for compressive strength and elastic modulus testing to achieve integrated measurement of concrete mechanical properties [35-37] (see Figure 2).

\section{Numerical Simulation and Analysis}

3.1. Finite Element Model. The reinforced concrete beam was $3,200 \mathrm{~mm}$ long $\times 200 \mathrm{~mm}$ wide $\times 400 \mathrm{~mm}$ high and was simulated with the finite element software Midas FEA. The materials in the model were isotropic and linear elastic. Moreover, the model had a total of 137,089 nodes and 66,096 solid elements, either hexahedral or octahedral, and the rebar element was a $1 \mathrm{D}$ line element. The concrete strength was C40 grade, for which the elastic modulus $E_{\mathrm{C}}$ was $32.5 \mathrm{GPa}$, Poisson's ratio was 0.2 , and the bulk density was $2.5 \mathrm{t} / \mathrm{m}^{3}$. The strength grade of the stirrup and upper frame rebar was HPB300, for which the elastic modulus $\mathrm{E}_{\mathrm{S} 300}=210 \mathrm{GPa}$. The strength grade of the bottom tensile rebar was HRB400, for which the elastic modulus $\mathrm{E}_{\mathrm{S} 400}=200 \mathrm{GPa}$. Poisson's ratio of the rebar element was 0.3 ; the bulk density was $7.80 \mathrm{t} / \mathrm{m}^{3}$. The maximum designed bearing load capacity of the beam $F=80 \mathrm{kN}$. Considering the internal force distribution in the beam and the distribution position of the rebar, the position of the drilling hole was simulated, and the front and side of the $1 / 4$ span from the end were selected. The surfaces perpendicular to the load were called the front side, those parallel to the load were called the side face, and the side bore was close to that of the front. According to the "Technical Code for Testing Concrete Strength by the Core-Drilling Method [35]," suitable borehole diameters include $100 \mathrm{~mm}, 75 \mathrm{~mm}$, and $50 \mathrm{~mm}$, wherein the depth of each drilling step is $5 \mathrm{~mm}$ and the total drilling depth is 60-100 mm (see Figure 3).

\subsection{Simulation Results}

3.2.1. Influence of the Borehole Diameter. Under the action of a dead weight and a $32 \mathrm{kN}$ load (no more than $60 \%$ of the yield strength of the concrete material to avoid effects from plasticity [38]), the average stress within the solid elements of the three different sized boreholes was extracted as the stress change before and after core drilling. For the same borehole diameter, front or side core drilling can achieve stress relief. However, the front core-drilling stress was closest to the maximum compressive stress of the concrete in the compression zone, so front core drilling was suitable for practical measurement applications. The change in stress with respect to the depth of the drill core is shown in Table 1 and Figure 4.

Figure 4 shows that the stress release trend was the same for different borehole diameters. Taking the drilling depth as the abscissa, the stress in the area to be measured will go through two stages during the drilling process. In the first stage, the stress is released quickly. As the hole depth increases, the stress gradually decreases until the stress is released completely. The drilling depth corresponding to the complete release of stress is called the zero-stress depth, which is reached for the first time after the end of the first stage. If the hole depth continues to increase, the stress release enters the second stage. At this point, the stress increases in the inverse direction until reaching a maximum value (which is much less than the initial stress and is basically equal for the different borehole diameters), and then the inverse stress gradually approaches the zero-stress depth again. In the actual stress measurement, the zero-stress depth from the first stage is the primary focus. The smaller the borehole diameter, the greater the stress release rate, the faster the complete stress release, and the smaller the zerostress depth.

3.2.2. Analysis of the Stress Concentration Range around the Borehole. After drilling, stress mutations and concentrations will occur in localized areas of the concrete, resulting in local stress redistribution. For the structure, changes in local stress may result in more widespread changes in the force on 


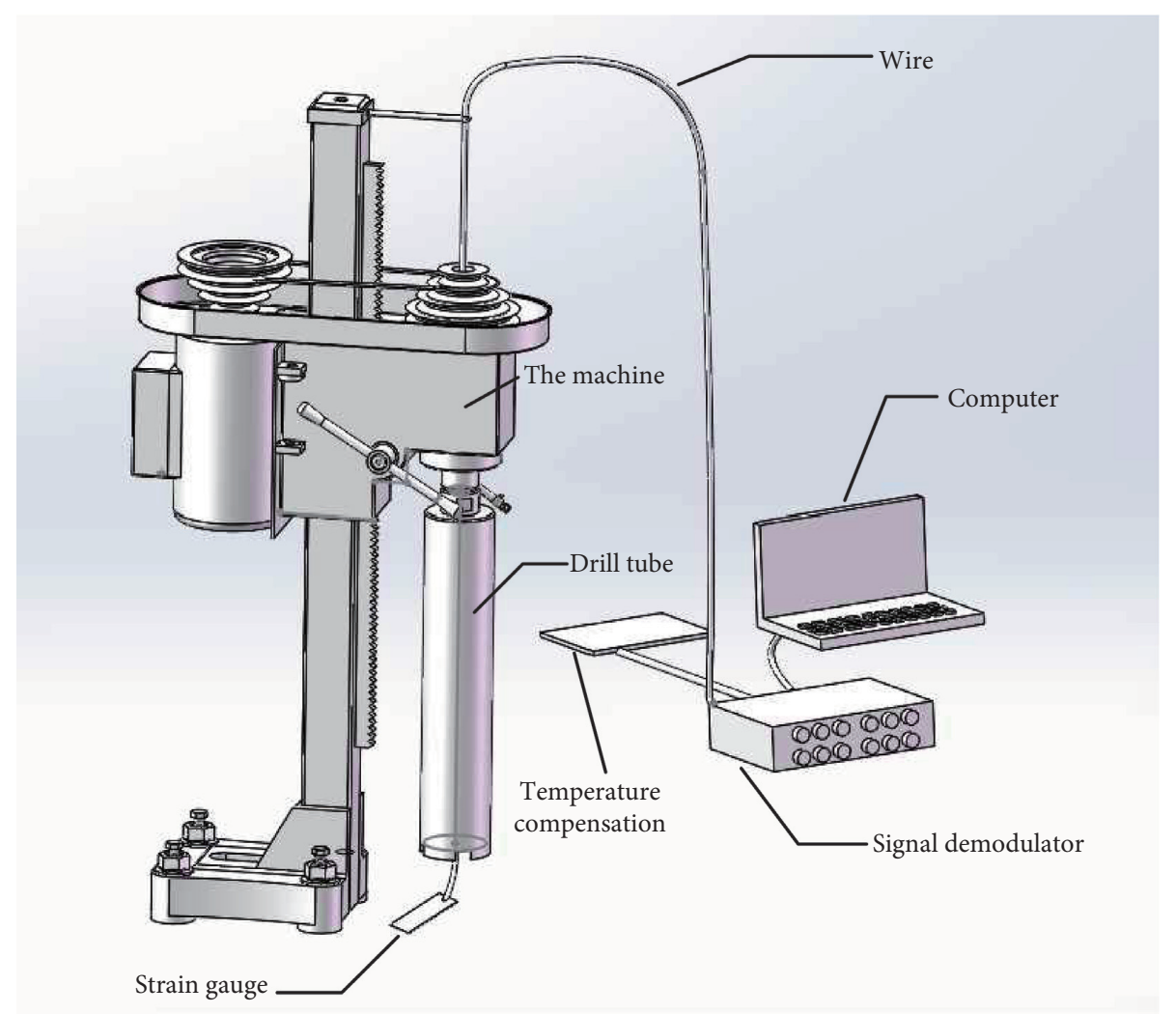

FIGURE 2: Special core-drilling measurement system.

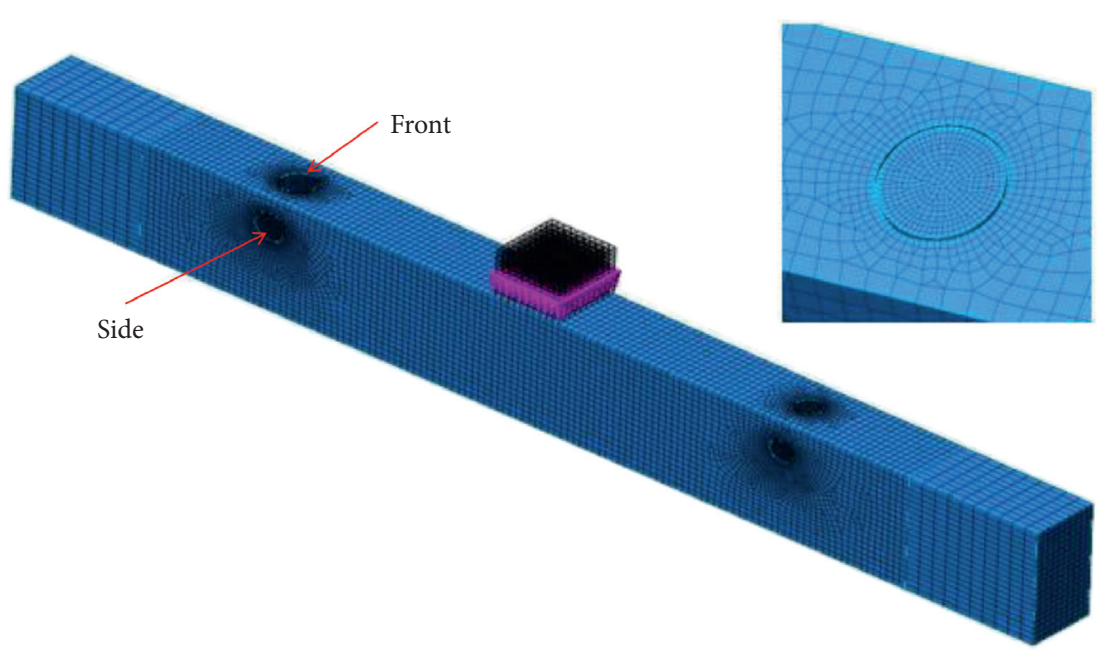

FIgURE 3: Drill hole position, meshing, and loading diagram.

the structure, affecting its mechanical performance. For boreholes used to measure the in situ stress within concrete, the location of adjacent holes should be beyond the local influence of the respective boreholes, according to SaintVenant's principle. In the actual measurement, strain sensors should be arranged around the borehole, which can sensitively and accurately measure the strain changes caused by the core drilling within a certain range. Beyond that range, the sensitivity of the strain sensor becomes weak, which may lead to the failure of the strain measurement. The stress values at different depths in locations near and far from the borehole were extracted to analyse the stress concentration range around the borehole.

As shown in Figure 5, the closer the measuring point is to the hole, the greater the stress change is. The closer it is to the outer edge of the borehole wall, the closer the stress change curve is to the stress-drilling depth curve (Figure 4). This phenomenon is especially obvious in the range of $0-15 \mathrm{~mm}$, which can be used as a location for the externally pasted strain gauge. When the borehole diameter is $100 \mathrm{~mm}$, the 
TABLE 1: Stress data from boreholes of various diameters.

\begin{tabular}{lcccc}
\hline $\begin{array}{l}\text { Depth } \\
(\mathrm{mm})\end{array}$ & $\begin{array}{c}100 \mathrm{~mm} \text { diameter front } \\
\text { borehole stress }(\mathrm{MPa})\end{array}$ & $\begin{array}{c}75 \mathrm{~mm} \text { diameter front } \\
\text { borehole stress }(\mathrm{MPa})\end{array}$ & $\begin{array}{c}50 \mathrm{~mm} \text { diameter front } \\
\text { borehole stress }(\mathrm{MPa})\end{array}$ & $\begin{array}{c}50 \mathrm{~mm} \text { diameter side } \\
\text { borehole stress }(\mathrm{MPa})\end{array}$ \\
\hline 0 & -2.37 & -2.35 & -2.25 & -1.32 \\
5 & -2.28 & -2.25 & -1.98 & -0.85 \\
10 & -2 & -1.63 & -1.01 & -0.35 \\
15 & -1.55 & -1.02 & -0.24 & -0.01 \\
20 & -1.05 & -0.44 & 0.18 & 0.09 \\
25 & -0.63 & -0.07 & 0.27 & 0.12 \\
30 & -0.29 & 0.13 & 0.22 & 0.07 \\
35 & -0.01 & 0.22 & 0.17 & 0.06 \\
40 & 0.1 & 0.24 & 0.13 & 0.04 \\
45 & 0.18 & 0.22 & 0.08 & 0 \\
50 & 0.23 & 0.17 & 0.04 & 0 \\
55 & 0.25 & 0.15 & 0 & 0 \\
65 & 0.23 & 0.12 & 0 & 0 \\
70 & 0.21 & 0.12 & 0 & 0 \\
\hline
\end{tabular}

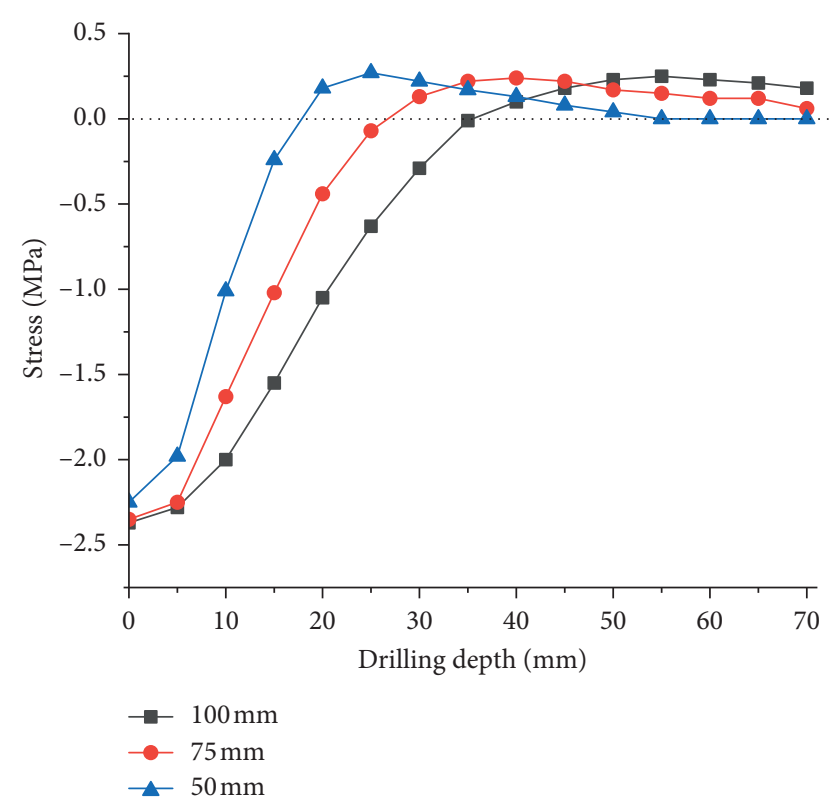

FIgURE 4: Relationship between stress and drilling depth for different borehole diameters.

stress variation range reaches $180 \mathrm{~mm}$ away from the borehole wall, and the stress-drilling depth curve is a straight line (i.e., it is not affected by the core drilling). The stress concentration range for this borehole diameter is approximately $0-180 \mathrm{~mm}$. When the borehole diameter is $75 \mathrm{~mm}$, the stress concentration range is approximately $0-160 \mathrm{~mm}$. When the borehole diameter is $50 \mathrm{~mm}$, the stress concentration range is approximately $0-140 \mathrm{~mm}$. The larger the borehole diameter, the larger the local influence scope of the borehole. Hence, adjacent boreholes should-at least-be kept outside the influence scope. Results. Table 2 describes the theoretical stresses from boreholes with diameters of $100 \mathrm{~mm}, 75 \mathrm{~mm}$, and $50 \mathrm{~mm}$, which were converted from the strains measured by three sizes of resistance strain gauges. The results show that, in the finite element simulation environment, the measured material is uniform, and the measurement results from the $50 \mathrm{AA}, 30 \mathrm{AA}, 20 \mathrm{AA}$, and 10AA strain gauges are nearly equal.

\section{Test and Results}

4.1. Test Process. Three reinforced concrete beams, which had the same dimensions as those in the simulation, were cast for verification testing. The load placed on each beam by the jack was $32 \mathrm{kN}$. The maximum diameter of the coarse aggregates in the concrete did not exceed $20 \mathrm{~mm}$, and the concrete slump was $120 \pm 30 \mathrm{~mm}$. The other conditions were the same as those in the numerical simulation. Figure 6 shows the verification test of core drilling using this system.

Because the drill core has reasonably avoided the steel rebar, it is not necessary to consider the influence of the steel rebar on drilling. In actual engineering applications, a steel rebar detector can be used to identify the location of the steel rebar in advance. After each beam was set up, it was preloaded, and the instruments were checked to determine whether they were in working order. The drilling measurement was initiated after fixing the calibration position, sealing the strain gauge and the drill, connecting the signal line to the strain gauge and the reading meter, and connecting the delivery pipe. Each time the drill penetrated the concrete by another about $5 \mathrm{~mm}$ depth, the drilling was paused for $60 \mathrm{~min}$ to allow the heat from the drilling to dissipate, and a reading of the strain sensor was taken. The drilling continued until the strain data were basically unchanged, and the strain and drilling depth at that point were recorded.

\subsection{Experimental Results}

4.2.1. Results for Each Borehole Diameter. The data in Tables 3-5 show the stable strain values from each strain 


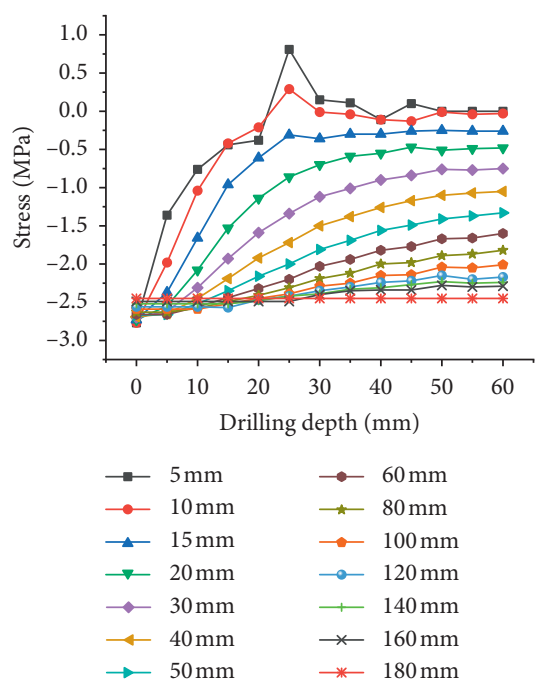

(a)

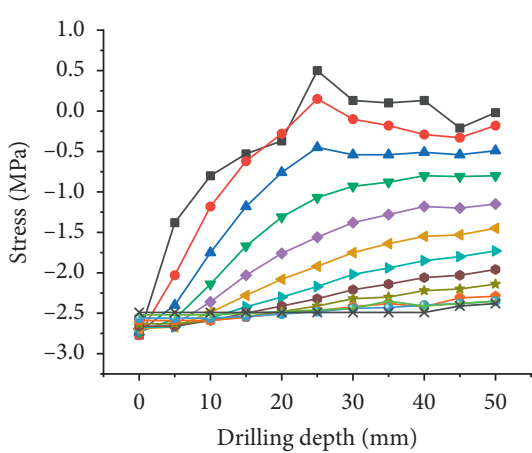

$\begin{array}{ll}\rightarrow 5 \mathrm{~mm} & \rightarrow 60 \mathrm{~mm} \\ \rightarrow 10 \mathrm{~mm} & \rightarrow 80 \mathrm{~mm} \\ \simeq 15 \mathrm{~mm} & \rightarrow 100 \mathrm{~mm} \\ \rightarrow-20 \mathrm{~mm} & \rightarrow 120 \mathrm{~mm} \\ \rightarrow-30 \mathrm{~mm} & \multimap 140 \mathrm{~mm} \\ \multimap 40 \mathrm{~mm} & \rightarrow-160 \mathrm{~mm} \\ \rightarrow-50 \mathrm{~mm} & \end{array}$

(b)

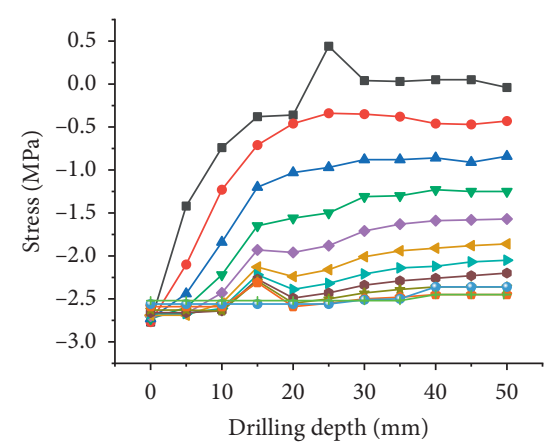

$$
\begin{array}{ll}
\rightarrow 5 \mathrm{~mm} & \rightarrow 50 \mathrm{~mm} \\
\rightarrow-10 \mathrm{~mm} & \rightarrow-60 \mathrm{~mm} \\
\rightarrow 15 \mathrm{~mm} & \rightarrow-80 \mathrm{~mm} \\
\rightarrow-20 \mathrm{~mm} & \rightarrow-100 \mathrm{~mm} \\
\rightarrow-30 \mathrm{~mm} & \rightarrow-120 \mathrm{~mm} \\
\longrightarrow 40 \mathrm{~mm} & \rightarrow 140 \mathrm{~mm}
\end{array}
$$

\begin{tabular}{|c|c|c|c|c|c|c|c|c|c|}
\hline \multirow[b]{2}{*}{ Gauge specification } & \multicolumn{2}{|c|}{$\begin{array}{l}100 \mathrm{~mm} \text { diameter } \\
\text { front borehole }\end{array}$} & \multicolumn{3}{|c|}{$75 \mathrm{~mm}$ diameter front borehole } & \multicolumn{2}{|c|}{$\begin{array}{l}50 \mathrm{~mm} \text { diameter } \\
\text { front borehole }\end{array}$} & \multicolumn{2}{|c|}{$\begin{array}{l}50 \mathrm{~mm} \text { diameter } \\
\text { side borehole }\end{array}$} \\
\hline & $50 \mathrm{AA}$ & $20 \mathrm{AA}$ & $30 \mathrm{AA}$ & $20 \mathrm{AA}$ & $10 \mathrm{AA}$ & $20 \mathrm{AA}$ & $10 \mathrm{AA}$ & $20 \mathrm{AA}$ & $10 \mathrm{AA}$ \\
\hline Stress $(\mathrm{MPa})$ & -2.33 & -2.37 & -2.32 & -2.35 & -2.4 & -2.25 & -2.28 & -1.27 & -1.32 \\
\hline
\end{tabular}

(c)

Figure 5: Influence range of boreholes with different diameters: (a) $100 \mathrm{~mm}$, (b) $75 \mathrm{~mm}$, and (c) $50 \mathrm{~mm}$.

TABle 2: Stress data from boreholes of different diameters determined using different strain gauges.

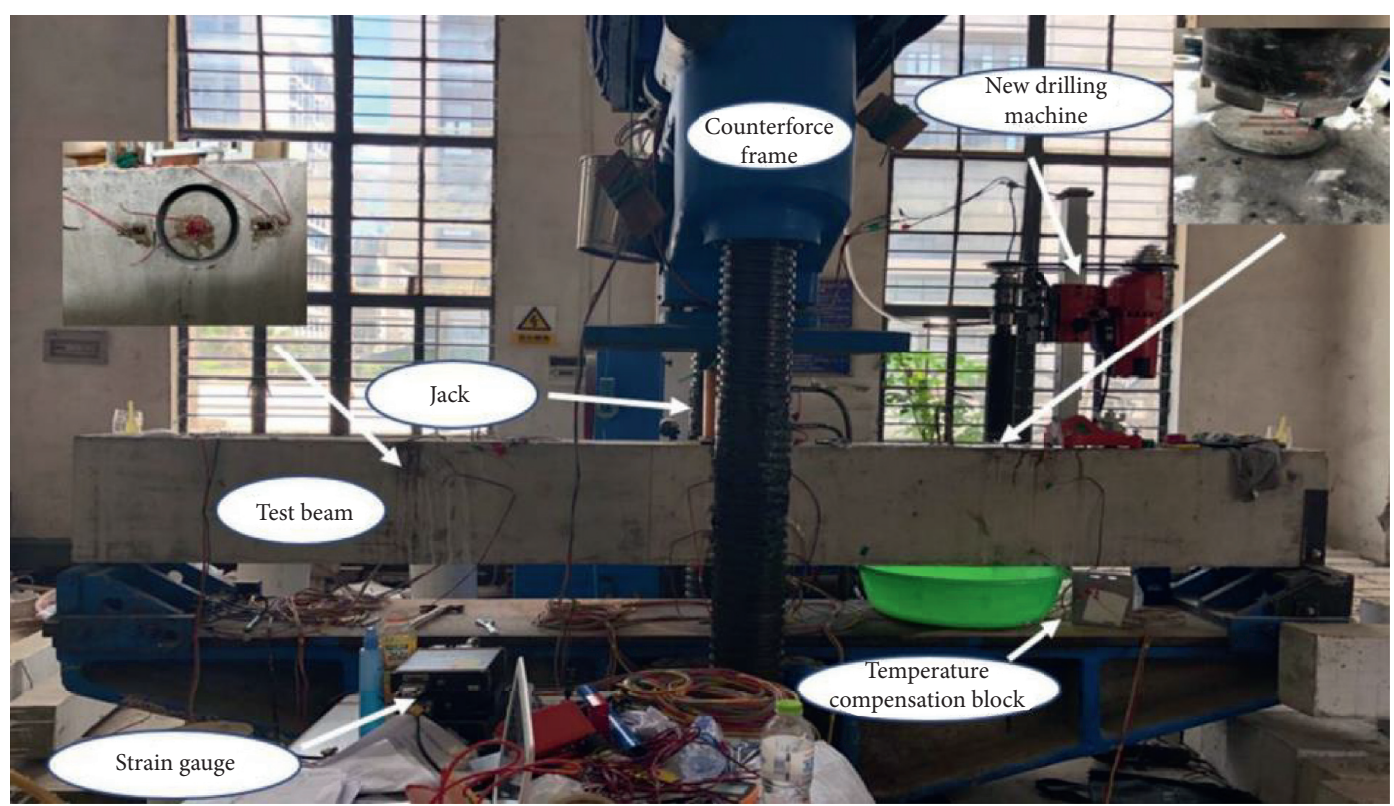

FIgURE 6: In situ stress test of a beam measured by the CDM.

gauge after drilling to different depths and waiting for $60 \mathrm{~min}$. The measurements taken from the first beam, second beam, and third beam are shown in Tables 3-5, respectively.

Strain gauges of different sizes can be used to measure the strain released from the three different sized boreholes.
However, the results from different sized strain gauges can differ greatly, which is most obviously reflected in strain gauges with short grids, such as 10AA, wherein the grid is close to or even smaller than the maximum size of the coarse aggregates in the concrete. Another reason for the variation 
TABle 3: Experimental measurements collected from the first beam.

\begin{tabular}{lccc}
\hline Drilling depth $(\mathrm{mm})$ & & $75 \mathrm{~mm}$ diameter front borehole (front 1-2) & 10AA strain $(\mu \varepsilon)$ \\
\hline 0 & 30AA strain $(\mu \varepsilon)$ & -68 & -49 \\
7 & -66 & -59 & -42 \\
12 & -53 & -53 & -1 \\
17 & -39 & -40 & 0 \\
22 & -33 & -24 & 39 \\
27 & -23 & -7 & 46 \\
33 & -18 & -9 & 47 \\
36 & -15 & 4 & 32 \\
42 & -14 & 4 & -6 \\
47 & -20 & 5 & 0 \\
52 & -10 & -1 & 13 \\
60 & -2 & 0 & 1 \\
\hline
\end{tabular}

TABLE 4: Experimental measurements collected from the second beam.

\begin{tabular}{|c|c|c|c|c|c|c|}
\hline \multirow{2}{*}{$\begin{array}{l}\text { Drilling depth } \\
(\mathrm{mm})\end{array}$} & \multicolumn{2}{|c|}{$\begin{array}{l}50 \mathrm{~mm} \text { diameter front } \\
\text { borehole (front } 2-1 \text { ) }\end{array}$} & \multirow{2}{*}{$\begin{array}{l}\text { Drilling depth } \\
\qquad(\mathrm{mm})\end{array}$} & \multirow{2}{*}{$\begin{array}{c}50 \mathrm{~mm} \text { diameter side } \\
\text { borehole (side } 2-1) \\
\text { 10AA strain }(\mu \varepsilon)\end{array}$} & \multirow{2}{*}{$\begin{array}{l}\text { Drilling depth } \\
\quad(\mathrm{mm})\end{array}$} & \multirow{2}{*}{$\begin{array}{c}50 \mathrm{~mm} \text { diameter side } \\
\text { borehole (side } 2-2 \text { ) } \\
\text { 20AA strain }(\mu \varepsilon)\end{array}$} \\
\hline & $\begin{array}{l}\text { 20AA strain } \\
(\mu \varepsilon)\end{array}$ & $\begin{array}{l}\text { 10AA strain } \\
(\mu \varepsilon)\end{array}$ & & & & \\
\hline 0 & -70 & -78 & 0 & -37 & 0 & -41 \\
\hline 5 & -57 & -62 & 5 & -28 & 8 & -40 \\
\hline 10 & -31 & -29 & 11 & -13 & 15 & -21 \\
\hline 15 & -12 & -15 & 17 & -6 & 21 & -6 \\
\hline 19 & -8 & -9 & 23 & -1 & 27 & -3 \\
\hline 25 & -1 & -5 & 30 & 0 & 31 & 2 \\
\hline 31 & -1 & 3 & 36 & 0 & 40 & 2 \\
\hline 35 & 2 & 3 & 40 & 0 & & \\
\hline 40 & 1 & 1 & & & & \\
\hline
\end{tabular}

TABLE 5: Experimental measurements collected from the third beam.

\begin{tabular}{lcc}
\hline Drilling depth $(\mathrm{mm})$ & \multicolumn{2}{c}{$100 \mathrm{~mm}$ diameter front borehole (front 3-1) } \\
\hline 0 & 20AA strain $(\mu \varepsilon)$ & -76 \\
6 & -70 & -71 \\
11 & -64 & -53 \\
15 & -49 & -46 \\
20 & -44 & -40 \\
27 & -35 & -28 \\
32 & -31 & -18 \\
36 & -13 & -14 \\
42 & -10 & -8 \\
47 & -8 & -5 \\
52 & -3 & 0 \\
56 & 5 & 4 \\
62 & 7 & 4 \\
70 & 4 & 3 \\
\hline
\end{tabular}

in strain measurements is the inhomogeneity and randomness of concrete materials. Therefore, when measuring, it is advisable to arrange different sized strain gauges in the borehole to collect strain release information, which can reduce the measurement error caused by the discreteness of the concrete material, thereby improving the accuracy of the stress evaluation.
4.2.2. Comparison of the Numerical and Experimental Results. Several core-drilling tests were carried out in this study. In each serial number in Tables 6-8, the word "front" denotes the front borehole and the word "side" denotes the side borehole, whereas the first number denotes the ordinal number of the beam and the second number denotes the position of the borehole. 
TABLE 6: Comparison of numerical and experimental in situ stress results for the concrete of the first beam.

\begin{tabular}{lccccccc}
\hline $\begin{array}{l}\text { Diameter } \\
(\mathrm{mm})\end{array}$ & $\begin{array}{c}\text { Serial } \\
\text { number }\end{array}$ & $\begin{array}{c}\text { Strain gauge } \\
\text { specification }\end{array}$ & $\begin{array}{c}\text { Theoretical loaded } \\
\text { stress }(\mathrm{MPa})\end{array}$ & $\begin{array}{c}\text { Theoretical dead } \\
\text { weight stress }(\mathrm{MPa})\end{array}$ & $\begin{array}{c}\text { Theoretical stress (dead } \\
\text { weight and load) }\end{array}(\mathrm{MPa})$ & $\begin{array}{c}\text { Load and dead } \\
\text { weight }(\mathrm{MPa})\end{array}$ & $\begin{array}{c}\text { Error } \\
(\%)\end{array}$ \\
\hline 75 & Front & 30AA & -1.99 & -0.33 & -2.32 & -2.12 & 8.62 \\
& $1-2$ & 20AA & -2.01 & -0.34 & -2.35 & -2.18 & 7.23 \\
\hline
\end{tabular}

TABLE 7: Comparison of numerical and experimental in situ stress results for the concrete of the second beam.

\begin{tabular}{lccccccc}
\hline $\begin{array}{l}\text { Diameter } \\
(\mathrm{mm})\end{array}$ & $\begin{array}{c}\text { Serial } \\
\text { number }\end{array}$ & $\begin{array}{c}\text { Strain gauge } \\
\text { specification }\end{array}$ & $\begin{array}{c}\text { Theoretical loaded } \\
\text { stress }(\mathrm{MPa})\end{array}$ & $\begin{array}{c}\text { Theoretical dead } \\
\text { weight stress }(\mathrm{MPa})\end{array}$ & $\begin{array}{c}\text { Theoretical stress (dead } \\
\text { weight and load) }(\mathrm{MPa})\end{array}$ & $\begin{array}{c}\text { Load and dead } \\
\text { weight }(\mathrm{MPa})\end{array}$ & $\begin{array}{c}\text { Error } \\
(\%)\end{array}$ \\
\hline & & & 20AA & -1.91 & -0.34 & -2.25 & -2.24 \\
50 & Front 2-1 & 10AA & -1.94 & -0.34 & -2.28 & 0.4 \\
& Side 2-1 & 10AA & -1.05 & -0.27 & -1.32 & -2.5 \\
& Side 2-2 & 20AA & -1.10 & -0.17 & -1.27 & -1.19 \\
\hline
\end{tabular}

TABLE 8: Comparison of numerical and experimental in situ stress results for the concrete of the third beam.

\begin{tabular}{lccccccc}
\hline $\begin{array}{l}\text { Diameter } \\
(\mathrm{mm})\end{array}$ & $\begin{array}{c}\text { Serial } \\
\text { number }\end{array}$ & $\begin{array}{c}\text { Strain gauge } \\
\text { specification }\end{array}$ & $\begin{array}{c}\text { Theoretical loaded } \\
\text { stress }(\mathrm{MPa})\end{array}$ & $\begin{array}{c}\text { Theoretical dead } \\
\text { weight stress }(\mathrm{MPa})\end{array}$ & $\begin{array}{c}\text { Theoretical stress (dead } \\
\text { weight and load) }\end{array}(\mathrm{MPa})$ & $\begin{array}{c}\text { Load and dead } \\
\text { weight }(\mathrm{MPa})\end{array}$ & $\begin{array}{c}\text { Error } \\
(\%)\end{array}$ \\
\hline \multirow{2}{*}{100} & \multirow{2}{*}{ Front 3-1 } & 20AA & -2.03 & -0.34 & -2.37 & -2.24 & 5.5 \\
& 50AA & -2.00 & -0.33 & -2.33 & -2.44 & 4.7 \\
\hline
\end{tabular}

The concrete test blocks made during pouring were used to measure the elastic modulus of these experimental beams, and the elastic modulus was $E_{\mathrm{S}}=32.046 \mathrm{GPa}$ (in practical engineering applications, the elastic modulus of concrete can also be measured by removing the drilled core samples [37]). The strain measured by the strain gauges was used to obtain the stress value (which was calculated by (1)) at the measuring point, which was compared with the theoretical stress calculated by the finite element method. Table 6 shows a comparison of the numerical and experimental results for the first beam with a borehole diameter of $75 \mathrm{~mm}$. The theoretical loaded stress according to the 30AA strain gauge reading was $-2.32 \mathrm{MPa}$, whereas the test value was $-2.12 \mathrm{MPa}$, which corresponds to an error of $8.62 \%$. The theoretical loaded stress according to the 20AA strain gauge reading was $-2.35 \mathrm{MPa}$, whereas the test value was $-2.18 \mathrm{MPa}$, which corresponds to an error of $7.23 \%$.

Table 7 shows a comparison of the numerical and experimental results for the second beam with a borehole diameter of $50 \mathrm{~mm}$. When the borehole position was front 21 , the theoretical loaded stress according to the 20AA strain gauge reading was $-2.25 \mathrm{MPa}$, whereas the test value was $-2.24 \mathrm{MPa}$, which corresponds to an error of $0.4 \%$. At the same borehole position, the theoretical loaded stress according to the $10 \mathrm{AA}$ strain gauge reading was $-2.28 \mathrm{MPa}$, whereas the test value was $-2.5 \mathrm{MPa}$, which corresponds to an error of $8.80 \%$. When the borehole position was side 2-1, the theoretical loaded stress according to the 10AA strain gauge reading was $-1.32 \mathrm{MPa}$, whereas the test value was $-1.19 \mathrm{MPa}$, which corresponds to an error of $9.85 \%$. When the borehole position was side 2-2, the theoretical loaded stress according to the 20AA strain gauge reading was $-1.27 \mathrm{MPa}$, whereas the test value was $-1.31 \mathrm{MPa}$, which corresponds to an error of $3.15 \%$.
Table 8 shows a comparison of the numerical and experimental results for the third beam with a borehole diameter of $100 \mathrm{~mm}$. When the borehole position was front 31 , the theoretical loaded stress according to the 20AA strain gauge reading was $-2.37 \mathrm{MPa}$, whereas the test value was $-2.24 \mathrm{MPa}$, which corresponds to an error of 5.5\%. At the same borehole position, the theoretical loaded stress according to the 50AA strain gauge reading was $-2.33 \mathrm{MPa}$, whereas the test value was $-2.44 \mathrm{MPa}$, which corresponds to an error of $4.7 \%$.

\section{Conclusion}

A special core-drilling measurement system was developed to research the stress released by concrete beams through simulations and experiments. Based on the analysis results, the following conclusions were obtained:

(1) A set of special measuring systems was developed for core drilling, which solved the problem of strain gauge connections within the borehole and provided an online integrated measurement of strain in the drill core in real time. Moreover, this setup can also perform integrated measurements of concrete mechanical properties.

(2) The stress measurement results from the finite element simulations showed that the strain gauge size had a very small effect on the results. However, in actual measurement applications, the strain gauge size is too big easily to be influenced by mechanical drilling and dynamic interference, and the size is too small easily to be influenced by the discreteness of the concrete material. Hence, different sized strain gauges were pasted in the same borehole to acquire 
strain measurements, which can reduce the measuring error caused by the discreteness of the concrete material, thereby improving the accuracy of the stress evaluation.

(3) When stress was released, the inner part of the borehole was more sensitive and accurate than the outer part of the borehole. The closer the outer part of the borehole was to the borehole wall, the closer the stress release curve was to that in the inner part of the borehole. This phenomenon was especially true in the range of $0-15 \mathrm{~mm}$, which can be used as a position for installing the strain gauges outside the borehole. When a structural member requires multiple core-drilling stress release processes, each borehole must be placed farther apart than the corresponding stress concentration range.

(4) A relationship between stress release and drilling depth was obtained from the finite element simulations. In the first drilling stage, the stress release rate was relatively high, and then the rate gradually decreased. After the stress reached zero for the first time, as the drilling continued, the stress at the point of measurement generated less tensile deformation due to the compression of adjacent points, and less tensile stress was generated in the later stage and then slowly released to zero again. The smaller the core diameter was, the smaller the depth required for the complete release of stress was and the less the damage to the structure was. The test results showed that drilling core diameters of $100 \mathrm{~mm}, 75 \mathrm{~mm}$, and $50 \mathrm{~mm}$ can be used to measure the stress release. In consideration of the local damage caused by drilling, a hole diameter of $50 \mathrm{~mm}$ should be preferred.

(5) It is feasible to measure the in situ stress of concrete beams by the CDM, and the measurement error may be limited to less than $10 \%$; the average error in this study was only $6.03 \%$, which can solve the problem of low measurement accuracy.

\section{Discussion}

The core-drilling stress relief method is used to measure the in situ stress within components. The application of the CDM in metal components is very mature, whereas much research is still required before this approach can be widely adopted for concrete materials. The uniformity and compactness of concrete materials are not as good as those of metal materials, so there are many interference factors that lead to low measurement accuracy. Although many studies have been performed in this area, the research has not been comprehensive, there is not a large number of experiments and engineering data to support the reported conclusions, and no set of special equipment systems has been developed for measurement [31-34].

The core-drilling measurement system developed in this paper can be used to evaluate the in situ stress within concrete structures. Moreover, the system can provide integrated measurements of concrete mechanical properties
[35-37]. However, the system weight needs to be decreased and the drilling stability needs to be improved. Compared with DIC systems $[15,20,23]$, the proposed system is easier to install and operate and the strain observation is more intuitive. However, in complex stress fields, the proposed method is temporarily inferior to DIC. In addition, on the basis of summarizing the existing research, this paper also uses FEA to simulate the stress released by a reinforced concrete beam during core drilling. The conclusions in this study were consistent with those in the literature $[8,28,34]$ : in an ideal environment, the two-stage stress relief curves and the influence range of the core drilling can be used to avoid the mutual interference of the core drilling and select the best fixed position for the strain gauge. The novelty of this study is that the core-drilling process is also tested and verified under the same conditions, which is different from many studies that are only simulations $[6,33]$ or only experiments [10,30]. On the basis of research [4], the rules for the diameter of the borehole and the size of the sensitive grid of the strain gauge were explored. Figure 4 shows that the stress release rule for each borehole diameter was the same, but the stress in the small borehole was completely released quickly, and the damage to the structure was small. Hence, the small borehole size should be given priority when measuring concrete. Tables $2-5$ show that, in the simulation process, the size of the strain gauge only slightly affected the measurement results, whereas there was a notable influence during the experiment. In fact, small strain gauges will be affected by the coarse aggregates in the concrete, whereas excessively large strain gauges will be limited by the borehole size. Therefore, the combination of borehole diameter and strain gauge size was very important, and it can be matched according to the characteristics of the concrete materials. Based on the study $[15,20]$, the interference of factors such as the concrete material aggregate size distribution, water, and temperature is considered, and the study is more comprehensive. Through a comparison of the simulation and test results, it was found that the strain data in Tables 3-5 had the same release rule with respect to the coredrilling depth as the simulation. However, some strain gauges were still substantially disturbed, indicating that the measurement system can be used to evaluate the stress in uniaxial concrete beams, and this process can be further optimized. Tables 6-8 compare the calculated values of 8 measurement points with the theoretical values. The maximum error was $9.85 \%$, the minimum error was $0.4 \%$, and the average error was only $6.03 \%$, which can solve the problem of low measurement accuracy. Overall, the research can improve the accuracy and practicality of concrete stress measurements and offers a technical reference for concrete stress detection, thereby providing a basis for structural diagnosis and reinforcement maintenance.

In this paper, only eight core-drilling tests were carried out on three beams. The test results showed that the proposed method and the developed system were feasible and that the provided accuracy can match that in the existing research $[4,6,15]$. However, before this method and system can be used in practice, the feasibility and accuracy need to be further confirmed by a large number of experiments. During the tests, 
multiple strain gauges were arranged in each borehole to prevent data loss and ensure accuracy. There were some strain gauge measurement failures when reading the data, which were mainly affected by the characteristics of the coarse aggregates in the concrete. Hence, we should develop a new strain sensor that is accurate and independent of material properties. In addition, this study only evaluated the compressive stress on the concrete surface and did not identify the stress gradient and other stresses along the depth of the concrete. Future studies can also use the IF method to evaluate the concrete stress form and study the bidirectional and multidirectional stress fields in complex concrete structures.

\section{Data Availability}

The data used to support the findings of this study are included within the article.

\section{Conflicts of Interest}

The authors declare that there are no conflicts of interest regarding the publication of this paper.

\section{Acknowledgments}

This project was supported by the Scientific Research Foundation of Guangxi University (XTZ150324), the National Natural Science Foundation of China (51868006), a Key R\&D Project of the Guangxi Science and Technology Program (Guike AB17292018), a cultivation program jointly founded by the Guangxi Natural Science Foundation of China (2018GXNSFAA138067), and a High-Level Innovation Team and Outstanding Scholar Plan of the Guangxi High Colleges.

\section{References}

[1] S. H. He, X. M. Zhao, J. Ma et al., "Review of highway bridge inspection and condition assessment," China Journal of Highway and Transport, vol. 30, no. 11, pp. 63-80, 2017.

[2] S. P. Liu, Z. X. Qi, and J. Qi, “100,000 dangerous bridges draw attention to china's road bridges entering a new era of construction and maintenance," 2016.

[3] F. P. Zhang, Z. G. Qiu, and P. F. Jiao, "Test analysis of measuring working strains in concrete structures by loopholedrilling strain-gage method," Advanced Materials Research, vol. 243-249, pp. 5656-5661, 2011.

[4] X. Ruan and Y. Zhang, "In-situstress identification of bridge concrete components using core-drilling method," Structure and Infrastructure Engineering, vol. 11, no. 2, pp. 210-222, 2015.

[5] M. V. Kurlenya, V. D. Baryshnikov, and L. N. Gakhova, "Experience with the paralle-hole method for estimation OF the active stresses IN a concrete mass," Hydrotechnical Construction, vol. 32, no. 9, pp. 540-544, 1998.

[6] C. Trautner, M. McGinnis, and S. Pessiki, "Analytical and numerical development of the incremental core-drilling method of non-destructive determination of in-situ stresses in concrete structures," Journal of Strain Analysis, vol. 45, 2010.

[7] C.-W. Chang, P. H. Chen, and H. S. Lien, "Evaluation of residual stress in pre-stressed concrete material by digital image processing photoelastic coating and hole drilling method," Measurement, vol. 42, no. 4, pp. 552-558, 2009.

[8] H. Zhang and H. N. Li, "Dynamic analysis of reinforced concrete structure with strain rate effect," Materials Research Innovations, vol. 15, no. 1, pp. s213-s216, 2011.

[9] C. X. Zhuang, J. Q. Zhang, and H. G. Jiang, "Review of concrete stress testing technologies," Journal of Highway and Transportation Research and Development, vol. 33, no. 3, pp. 43-51, 2016.

[10] Y. Yong, C. Wang, and X. S. Zhu, "Measurement and analysis of existing stress in concrete bridge structures," Journal of Tongji University, vol. 27, no. 2, pp. 198-202, 1999.

[11] J. Mathar, "Determination of initial stresses by measuring the deformation around drilled holes," Transactions of ASME, vol. 56, no. 4, pp. 249-254, 1934.

[12] D. V. Mirbach, "Hole-drilling method for residual stress measurement-consideration of elastic-plastic material properties," Materials Science Forum, vol. 768-769, pp. 174-181, 2014.

[13] N. J. Rendle and I. Vigness, "Hole-drilling Strain gage method of measuring residual stresses," Experimental Mechanics, vol. 6, no. 12, pp. 577-586, 1966.

[14] ASTM E837-08el, Standard Test Method for Determining Residual Stresses by the Hole-Drilling Strain-Gage Method, ASTM E837-08el, USA, 2008.

[15] M. J. McGinnis and S. Pessiki, "Experimental study of the core-drilling method for evaluating in-situ stresses in concrete structures," Journal of Materials in Civil Engineering, vol. 6, pp. 1-9, 2015.

[16] S. Mehrkar-Asl, "Concrete stress-relief coring: theory and application," Proceedings of the FIP Symposium on Post-tensioned Concrete Structures, vol. 6, pp. 569-576, 1996.

[17] S. Pessiki and H. Turker, "Theoretical formulation of the core drilling method to evaluate stresses in concrete structures," AIP Conference Proceedings, vol. 509, pp. 1731-1737, 2000.

[18] H. Turker and S. Pessiki, "Theoretical development of the core-drilling method for nondestructive evaluation of stresses in concrete structures," Center for Advanced Technology for Large Structural Systems, Lehigh University, Bethlehem, Pennsylvania, USA, 2003.

[19] D. Vangi and S. Tellini, "Hole-drilling strain-gauge method residual stress measurement with plasticity effects," Journal of Engineering Materials and Technology, vol. 132, p. 7, 2010.

[20] M. McGinnis, Experimental and Numerical Development of the Core-Drilling Method for the Nondestructive Evaluation of In-Situ Stresses in Concrete Structures, Lehigh University, Bethlehem, Pennsylvania, USA, 2006.

[21] G. S. Schajer, "Measurement of non-uniform residual stresses using the hole-drilling method. Part I-stress calculation procedures," Journal of Engineering Materials and Technology, vol. 110, no. 4, pp. 338-343, 1988.

[22] M. Beghini and L. Bertini, "Analytical expressions of the influence functions for accuracy and versatility improvement in the hole-drilling method," The Journal of Strain Analysis for Engineering Design, vol. 35, no. 2, pp. 125-135, 2000.

[23] C. Trautner, M. McGnnis, and S. Pessiki, "Application of the incremental core-drilling method to determine in-situ stresses in concrete," ACI Materials Journal, vol. 108, no. 3, pp. 290-299, 2011.

[24] Y. Zhang, X. Ruan, X. F. Shi et al., "Identification method for uniaxial in-situ stresses in bridge concrete structure," Engineering Mechanics, vol. 31, no. 11, pp. 154-160, 2014.

[25] Z. L. Feng and R. W. Lewis, "Optimal estimation ofin-situ ground stresses from displacement measurements," International Journal 
for Numerical and Analytical Methods in Geomechanics, vol. 11, no. 4, pp. 391-408, 1987.

[26] M. Y. Xu, G. J. Lin, and X. P. Sun, "Finite element analysis on effective stress of prestressed concrete beam based on hole -drilling method," Journal of Waterway and Harbor, vol. 29, no. 5, pp. 362-366, 2008.

[27] C. J. Zhao, L. F. Deng, and S. Z. Tian, "Numerical calculation on parameters of residual stresses measuring by hole-drilling method," Journal of Waterway and Harbor, vol. 32, no. 2, pp. 122-127, 2011.

[28] Z. G. Qiu and F. P. Zhang, "Numerical simulation of the releasing process of existing stress in concrete beam by drilling hole method," Journal of Harbin Institute of Technology, vol. 43, no. 1, pp. 232-236, 2011.

[29] C. Y. Feng, D. Y. Liu, and P. Yu, "Review of concrete stress release method," Bridge \& Tunnel Engineering, vol. 3, pp. 24-27, 2013.

[30] S. B. Santiago, "Stresses analysis at the altes museum of Berlin by means of the hole-drilling technique (donostia method)," Construction and Building Materials, vol. 21, pp. 1680-1687, 2007.

[31] K. Kesavan, K. Ravisankar, S. Parivallal, and P. Sreeshylam, "Technique to assess the residual prestress in prestressed concrete members," Experimental Techniques, vol. 29, no. 5, pp. 33-38, 2005.

[32] S. Parivallal, K. Ravisankar, K. Nagamani, and K. kesavan, "Core-drilling technique for in-situ stress evaluation in concrete structures," Experimental Techniques, vol. 35, no. 4, pp. 29-34, 2011.

[33] W. J. Yi and H. Xiang, "Testing and analyses OF the working stress OF rc columns," Industrial Construction, vol. 37, no. 1, pp. 52-56, 2007.

[34] Z. Y. Liu, D. N. Liu, and Q. Y. Jia, "Permanent prestress evaluation of prestressed concrete bridges in-service by holedrilling method," Journal of Wuhan Institute of Technology, vol. 34, no. 4, pp. 62-64, 2008.

[35] JGJ/T 384-2016, Technical Specification for Testing Concrete Strength with Drilled Core Method, JGJ/T 384-2016, China, 2016.

[36] M. EI-Moussaoui, R. K. Dhir, and P. Robery, "Potential use of small-diameter concrete cores for in situ compressive strength assessment," Magazine of Concrete Research, vol. 71, no. 15, pp. 809-826, 2019.

[37] GB/T 50081-2002, Standard for Test Method of Mechanical Properties on Ordinary Concrete, GB/T 50081-2002, China, 2002.

[38] M. Beghini, L. Bertini, A. Giri, C. Santus, and E. Valentini, "Measuring residual stress in finite thickness plates using the hole-drilling method," The Journal of Strain Analysis for Engineering Design, vol. 54, no. 1, pp. 65-75, 2019. 